\title{
COMPLEMENTATION AND RECOMBINATION BETWEEN METHIONINE-2 ALLELES IN NEUROSPORA CRASSA
}

\author{
NOREEN E. MURRAY* \\ Department of Microbiology, Birmingham University $\dagger$
}

Received 4.vi.6o

\section{INTRODUCTION}

AMONGST the many new methionine mutant strains of Neurospora crassa which have been isolated (Murray, I960) the sulphur requirement of forty-two is satisfied by homocysteine or methionine, but not by cystathionine. Heterocaryon tests show that the mutant genes in these strains are physiologically allelic with $\mathrm{H}_{98}$ and 48004 (me-2) and that some pairs of them exhibit the phenomenon of interallelic complementation.

Methionine-2 is located in the right arm of linkage group IV, in a region well supplied with genetic markers, and as interallelic crosses proved to be relatively fertile, it appeared that this gene would be suitable for the investigation of the relationship between genetic and complementation maps. The data from ordered tetrads (Murray, I960) indicated that $m e-2$ is 8.7 units distal to tryp-4 and 3.7 units proximal to pan-I. Therefore, tryp-4 and pan-I were chosen as suitable markers for the analysis of recombination between me-2 alleles.

The discovery of recombination between the two physiologically allelic mutants "Star" and " asteroid" in Drosophila (Lewis, I945), and more recently between alleles at loci in Aspergillus (Pritchard, 1955), Neurospora (Giles, I95I, I956; Mitchell, I955a, I.955b) and yeasts (Roman, I956; Leupold, I957), suggests that the gene may be interpreted as comprising a number of linearly arranged mutable sites which are separable by crossing-over. Pritchard (1955) was able to arrange a number of adenine alleles of Aspergillus in linear order by an analysis controlled by markers on each side of the locus. In general, recombination between the adenine alleles was accompanied by recombination of the associated markers. Prototroph formation was therefore explicable as the result of a single cross-over between the defective sites of the locus. Such a cross-over would produce one normal and one doubly mutant chromatid strand, and Pritchard was able to recover the doubly mutant recombinant. Other adenine prototrophs, of parental phenotype with respect to the marker genes, could not be interpreted as the products of single intragenic cross-overs, but were, perhaps, comparable in origin with the prototrophs from crosses of allelic pyridoxine mutants of Neurospora (Mitchell, I $\left.955^{a}, 1955^{b}\right)$. By studies of ordered tetrads Mitchell showed that

* Work done while holder of a postgraduate grant from the Department of Scientific and Industrial Research.

$\dagger$ Present address : Department of Biological Sciences, Stanford University, Stanford, California, U.S.A. 
prototroph formation was not accompanied by the formation of a reciprocal double mutant as would be expected if a cross-over had taken place. Evidence, therefore, suggests that two processes may be involved in interallelic recombination. The first is crossing-over (Pritchard, 1955); and the second is the non-reciprocal mechanism reported in Saccharomyces cerevisia (Lindegren, I953; Roman, 1956), in Neurospora crassa (Mitchell, I955a, I955b) and in Schizosaccharomyces pombe (Leupold, 1957). The term conversion will be used in this paper for the phenomenon of non-reciprocal recombination, but it is not intended to imply the mechanism of such an atypical segregation.

Case and Giles (1958a) have shown by tetrad analysis that recombination between two alleles at the pan-2 locus can occur, in the same cross, both by conventional crossing-over and by conversion. It seems probable that for different species, or even different genes of the same species, the relative frequencies of these two events may vary. In the present random spore analysis of interallelic recombination, where the analysis is controlled by closely linked markers on either side of the $m e-2$ locus, the mode of distribution of the prototrophs amongst the four combinations of marker genes will be influenced by the relative frequencies of interallelic crossing-over and conversion. If recombination occurs solely by crossing-over, in the absence of unexpected additional cross-overs between the $m e-2$ gene and the pan-I or tryp-4 markers, the methionine prototrophs should be recombinant with respect to the marker genes. In the cross tryp me-2 ${ }^{1}$ pan ${ }^{+} \times$ tryp $p^{+} m e-2^{2}$ pan an excess of methionine prototrophs of the recombinant genotype tryp $m e^{+}$pan would indicate the order tryp $m e-2^{2} m e-2^{1} p a n$, and conversely an excess of the recombinant genotype tryp $p^{+} e^{+} \mathrm{pan}^{+}$ would indicate the order tryp $m e-2^{1} m e-2^{2} p a n$, where $m e-2^{1}$ and $m e-2^{2}$ designate the actual sites of change in the $m e-2$ gene. Should prototroph formation result solely from conversion, the majority of the prototrophs would be expected to be non-recombinant with respect to the marker genes, unless conversion is favoured by crossing-over in the regions adjacent to the $m e-2$ gene. Most evidence (Mitchell, 1955a, 1955b; St Lawrence, 1956; Freese, 1957) indicates that there is a strong positive correlation between gene conversion and crossingover in the adjacent regions and this can result in an approximately equal distribution of the prototrophs amongst the four types of marker combinations. If both mechanisms operate in one cross an excess of methionine prototrophs, carrying one of the recombinant marker combinations, should be detectable (Case and Giles, I958b) providing that conversion is not sufficiently frequent to obscure the results of interallelic crossing-over.

\section{MATERIALS AND METHODS}

Of the strains used, $\mathrm{Hg} 8$ and 48004 were descendants of those isolated at Stanford prior to 1945 (see Barratt et al., 1954). $\mathrm{K}_{5}, \mathrm{~K}_{1} 8$ and $\mathrm{K}_{23}$ were isolated from the prototrophic stock Y8743 (Catcheside, 1954) and the remainder from Emerson $a$. The stocks used were heterocaryon compatible with an arginine 
mutant, $\mathrm{K}_{\mathrm{I} 32}$ (arg-5). Strains with an isolation number prefixed by the letter " $\mathrm{K}$ " were isolated by Catcheside and those with the prefix " $\mathrm{P}$ " by the author.

The media were as previously described (Murray, 1960) except that in plating experiments the sorbose concentration was increased to $\mathrm{I} \cdot \mathrm{O}$ per cent.

Evidence of complementation was sought in all the 946 possible pairs of combinations by a method which involved the inoculation of minimal sorbose medium with an aqueous suspension of conidia (Ahmad and Catcheside, 1960). The second component was superimposed after the water of the first one had become absorbed into the medium. The base of each Petri plate was marked out in a grid of halfinch squares arranged in five rows of five so that 25 pairwise combinations of mutants could be tested on each plate. Formation of a prototrophic heterocaryotic growth was easily detected from one to four days after inoculation. The tests were performed at least three times and were consistently reproducible. Positive results were retested singly, together with control tests of the two components.

The vigour of the interallelic heterocaryons was assayed as the dry weight of mycelial pads formed after four days' growth in liquid minimal medium at $25^{\circ} \mathrm{C}$. The flasks were not shaken continuously but were swirled three times a day to keep the mycelium submerged and to prevent conidiation.

Each of a sample of $m e-2$ alleles, chosen to represent the different physiological classes, was crossed to a stock, of genotype tryp-4 (Y2198), pan-I (553I) and fertile cultures of the required genotypes were extracted. Crosses were then made of the type tryp $m e-2^{1} p_{a n}+\times$ try $^{+} p^{+} m e-2^{2}$ pan where $m e-2^{1}$ and $m e-2^{2}$ are different alleles. Self-crosses, similarly marked, were made as controls.

The crosses were made in two-inch deep Petri dishes containing appropriately supplemented Westergaard's medium in which corrugated filter paper was embedded. The dishes were partially sealed by "sellotape" and incubated for approximately two weeks. At this stage spore shedding usually began and each Petri dish lid was replaced by a clean one, re-sealed, and the dishes incubated for a further two weeks in an inverted position. In this way large numbers of ascospores, almost free of mycelial contamination, were deposited on the Petri dish lid. The spores were washed off the lid in $\mathrm{O}^{\prime} \mathbf{I}$ per cent. agar and diluted to give approximately 20,000 viable spores per $\mathrm{ml}$.

A layer plating technique similar to that described by Newmeyer (1954) was used to screen the spores. A lower layer of approximately $15 \mathrm{ml}$. of a medium, composed of Vogel's basic salts mixture, I per cent. sorbose, o. I per cent. sucrose, and supplemented with tryptophan (50 mg./1) and pantothenic acid (10 mg./1), was poured into Petri plates. O.I ml. samples of heat-treated ascospore suspension were transferred to tubes containing $2 \mathrm{ml}$. of molten 0.5 per cent. agar medium and the contents of each tube were evenly distributed as the upper layer of a plate. The plates were inspected after 40 and 48 hours of incubation at $25^{\circ} \mathrm{C}$. and methionine-independent colonies isolated. Crosses involving combinations of alleles between which heterocaryon complementation had been detected yielded pseudowild types. However, these were usually not detectable until after three days of incubation. Only for crosses between $\mathrm{P}_{1} 69$ and $\mathrm{P}_{99}$ were pseudowild types detectable after $4^{8}$ hours' incubation and all isolates from these crosses were tested to determine whether they were true or pseudowild type with respect to the methionine gene.

Estimates of the numbers of viable ascospores were obtained from colony counts on plates supplemented with methionine, tryptophan and pantothenic acid, and with an upper layer containing $0^{\circ} \mathrm{I} \mathrm{ml}$. of spore suspension diluted to one-tenth of the previous concentration.

\section{RESULTS}

\section{(i) Heterocaryon complementation}

The formation of an observable growth within four days of inoculation was taken as evidence of complementation and by this 
criterion the mutants were divided into six groups (A-F). Fig. I $a$ represents the results in a two-dimensional pattern of reaction and fig. $\mathrm{I} b$ is a one-dimensional interpretation in which each mutant exerts a range of influence. These ranges of defective action are so drawn that overlapping ones occur where the heterocaryons do not grow on minimal medium and non-overlapping ranges where complementation results in growth of the heterocaryon. The particular complementation map shown is one of six possible sequences. Only

Locus me -2

Number in
each class

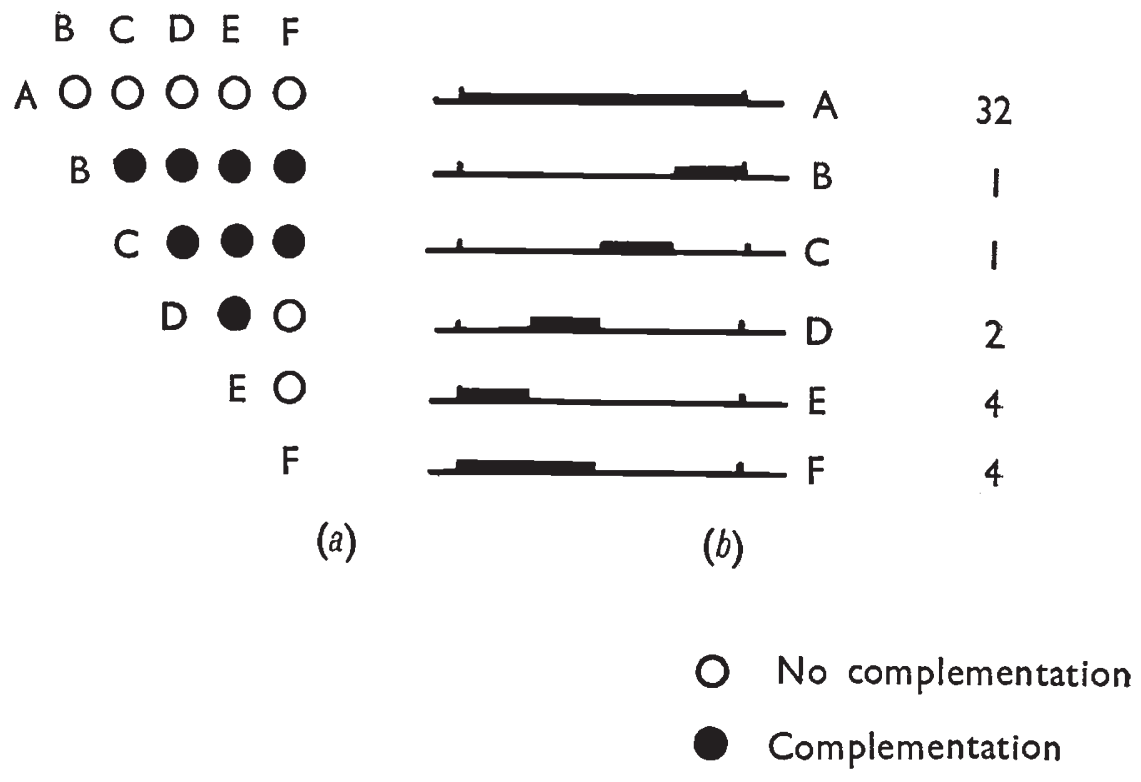

Fig. I.-Complementation matrix $(a)$ and map $(b)$ of methionine-2 mutants of Neurospora crassa. The numbers of mutants distinguished in each class is shown by the map.

the presence of group $\mathrm{F}$, whose range overlaps those of group $\mathrm{D}$ and $\mathrm{E}$, enables the latter two groups to be assigned to adjacent sites. The majority of the alleles are group A members, which show no complementation with any other alleles.

Woodward, Partridge and Giles (1958) found that the greater the distance between two ranges of action, as represented on the complementation map, the more vigorous was the heterocaryotic growth. More recently Woodward (1959) has confirmed this indication by enzyme assays on the in vitro complementation at the $a d-4$ locus. Enzyme assays of the me-2 interallelic heterocaryons have not been made, and the extent of complementation can only be assessed from growth assays and from the time taken for interallelic heterocaryons. to give a visible growth. Both these estimates are charted in table I and the alleles are arranged such that those giving the most vigorous. 
prototrophic growth are the most widely separated. If Woodward's findings were a general rule then the order predicted would be group B (Pr69), G (P8I), D (K 44$)$, E (P99). The heterocaryons $\mathrm{B}+\mathrm{C} ; \mathrm{C}+\mathrm{D}$ and $\mathrm{D}+\mathrm{E}$ are weakly prototrophic but the heterocaryon $\mathrm{B}+\mathrm{E}$ makes good growth in the absence of methionine.

(ii) Interallelic recombination

Strains $\mathrm{K}_{5}, \mathrm{P}_{2}$ (group A); $\mathrm{P}_{1} 69$ (B); P8I (C); K44 (D); H98, $\mathrm{P}_{99}, \mathrm{Pr}_{74}(\mathrm{E})$ and $\mathrm{K}_{23}(\mathrm{~F})$ were used in recombination studies.

TABLE I

Assays of the extent of interallelic complementation between methionine-2 alleles

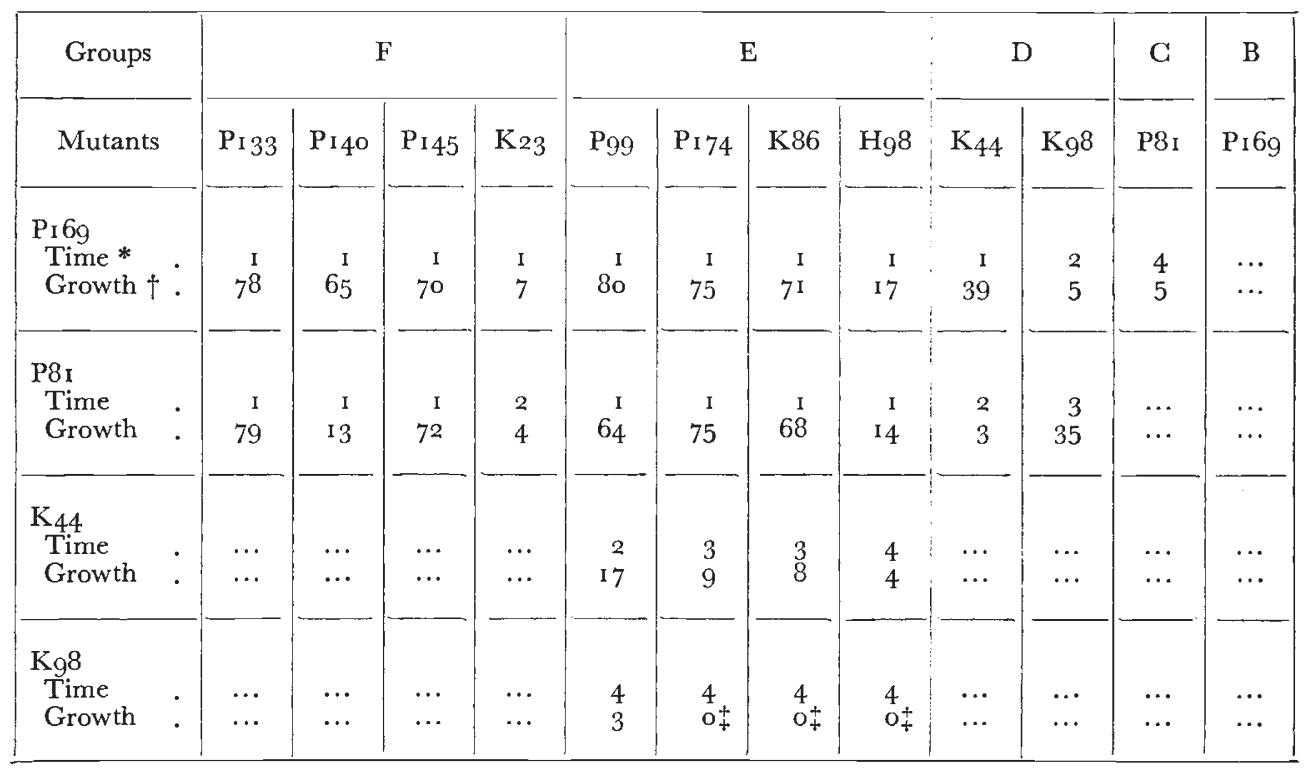

* Time in days taken for interallelic heterocaryons to become visible. $\dagger$ Dry weight assays expressed as a percentage of wild type weight.

$\ddagger$ Growth not weighable four days after inoculation.

(a) Self-crosses (table 2). The number of spores screened was restricted by the poor viability of spores from some of the self-crosses. Only one prototroph was observed in all the crosses and this is not a contaminant for it carried the pan-I marker; it is not known whether the prototrophy was due to a change at the $m e-2$ locus or to a mutation at a suppressor locus. Although it would be desirable to increase the number of spores screened the results indicate that the prototroph formation in interallelic crosses is not usually the result of reversion.

(b) Intragroup crosses (table 3). Methionine prototrophs were isolated from the group $\mathrm{A}$ crosses and from a cross between group $\mathrm{E}$ mutants. These results confirm that group A mutants are not deletions 
TABLE 2

Self-crosses

\begin{tabular}{|c|c|c|}
\hline \multirow{2}{*}{$\begin{array}{l}\text { Mutant } \\
\text { strains }\end{array}$} & \multicolumn{2}{|c|}{ No. of } \\
\hline & viable spores & prototrophs \\
\hline $\begin{array}{l}\mathrm{K}_{5} \\
\mathrm{P}_{2} \\
\mathrm{P}_{169} \\
\mathrm{P}_{11} \\
\mathrm{~K}_{44} \\
\mathrm{H}_{98} \\
\mathrm{P}_{99} \\
\mathrm{P}_{74} \\
\mathrm{~K}_{23}\end{array}$ & $\begin{array}{r}91,600 \\
89,000 \\
32,500 \\
95,500 \\
47,700 \\
73,800 \\
124,800 \\
50,600 \\
48,300\end{array}$ & $\begin{array}{l}\text { I } \\
0 \\
0 \\
0 \\
0 \\
0 \\
0 \\
0 \\
0\end{array}$ \\
\hline
\end{tabular}

TABLE 3

Analysis of prototrophs from intra- and inter-group crosses

\begin{tabular}{|c|c|c|c|c|c|c|c|c|}
\hline \multirow{3}{*}{$\begin{array}{c}\text { Cross } \\
\mathbf{P I} \times \mathbf{P}_{2}\end{array}$} & \multirow{3}{*}{$\begin{array}{l}\text { Comple- } \\
\text { mentation } \\
\text { groups } \\
\text { represented }\end{array}$} & \multirow{3}{*}{$\begin{array}{l}\text { No. of } \\
\text { viable } \\
\text { spores } \\
\text { screened }\end{array}$} & \multicolumn{2}{|c|}{ me-2 prototrophs } & \multicolumn{4}{|c|}{$\begin{array}{l}\text { No. of prototrophs in } \\
\text { the four classes }\end{array}$} \\
\hline & & & \multirow{2}{*}{ No. } & \multirow{2}{*}{$\begin{array}{l}\text { Frequency } \\
\text { per cent. }\end{array}$} & \multicolumn{2}{|c|}{ Parental } & \multicolumn{2}{|c|}{ Recombinant } \\
\hline & & & & & PI & $\mathbf{P}_{2}$ & ++ & pan tryp \\
\hline $\begin{array}{l}\mathrm{K}_{5} \text { pan } \times \mathrm{P}_{2} \text { tryp } \\
\mathrm{P}_{2} \text { pan } \times \mathrm{K}_{5} \text { tryp }\end{array}$ & $\begin{array}{l}\mathrm{A} \\
\mathrm{A}\end{array}$ & $\begin{array}{l}179,080 \\
146,220\end{array}$ & $\begin{array}{l}59 \\
62\end{array}$ & $\begin{array}{l}0.033 \\
0.042\end{array}$ & $\begin{array}{l}17 \\
19\end{array}$ & $\begin{array}{l}16 \\
25\end{array}$ & $\begin{array}{r}18 \\
8\end{array}$ & $\begin{array}{r}8 \\
10\end{array}$ \\
\hline $\mathrm{P}_{74}$ pan $\times \mathrm{P}_{99}$ tryp & $\mathbf{E}$ & 448,367 & 7 & $0 \cdot 0016$ & 2 & 3 & I & I \\
\hline $\begin{array}{l}\text { P81 pan } \times \text { Pi69 tryp } \\
\text { P169 pan } \times \text { P81 tryp }\end{array}$ & $\begin{array}{l}\mathbf{G} \times \mathbf{B} \\
\mathbf{B} \times \mathbf{G}\end{array}$ & $\begin{array}{l}5^{28,440} \\
3^{11}, 520\end{array}$ & $\begin{array}{l}9 \\
7\end{array}$ & $\begin{array}{l}0 \cdot 0017 \\
0 \cdot 0023\end{array}$ & $\begin{array}{l}0 \\
2\end{array}$ & $\begin{array}{l}2 \\
2\end{array}$ & $\begin{array}{l}7 \\
0\end{array}$ & $\begin{array}{l}0 \\
3\end{array}$ \\
\hline $\begin{array}{l}\text { P169 pan } \times \text { P99 tryp } \\
\mathrm{P}_{99} \text { pan } \times \text { PI69 trypp }\end{array}$ & $\begin{array}{l}\mathbf{B} \times \mathbf{E} \\
\mathbf{E} \times \mathbf{B}\end{array}$ & $\begin{array}{r}80,248 \\
276,417\end{array}$ & $\begin{array}{r}6 \\
14\end{array}$ & $\begin{array}{l}0.0075 \\
0.0051\end{array}$ & $\begin{array}{l}2 \\
3\end{array}$ & $\begin{array}{l}0 \\
4\end{array}$ & $\begin{array}{l}4 \\
0\end{array}$ & $\begin{array}{l}0 \\
7\end{array}$ \\
\hline 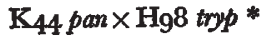 & $\mathbf{D} \times \mathbf{E}$ & 202,886 & $9^{I}$ & $0 \cdot 045$ & 6 & 39 & 6 & 40 \\
\hline $\begin{array}{l}\mathrm{K}_{23} \text { pan } \times \mathrm{H}_{98} \text { tryp } \\
\mathrm{H}_{98} \text { pan } \times \mathrm{K}_{23} \text { tryp }\end{array}$ & $\begin{array}{l}\mathbf{F} \times \mathbf{E} \\
\mathbf{E} \times \mathbf{F}\end{array}$ & $\begin{array}{l}334,590 \\
244,306\end{array}$ & $\begin{array}{l}\text { 109 } \\
\text { 103 }\end{array}$ & $\begin{array}{l}0 \cdot 033 \\
0.042\end{array}$ & $\begin{array}{l}17 \\
42\end{array}$ & $\begin{array}{l}3^{8} \\
13\end{array}$ & $\begin{array}{l}17 \\
30\end{array}$ & $\begin{array}{l}37 \\
18\end{array}$ \\
\hline $\mathrm{K}_{44}$ pan $\times \mathrm{K}_{23} \operatorname{tryp} \ddagger$ & $\mathbf{D} \times \mathbf{F}$ & 84,384 & 4 & $0 \cdot 0047$ & o & $\mathbf{o}$ & o & 4 \\
\hline $\begin{array}{l}\text { P81 pan } \times \mathrm{K}_{44} \text { tryp } \\
\mathrm{K}_{44 \text { pan } \times \text { P81 tryp }}\end{array}$ & $\begin{array}{l}\mathbf{C} \times \mathbf{D} \\
\mathbf{D} \times \mathbf{C}\end{array}$ & $\begin{array}{l}181,200 \\
133,630\end{array}$ & $\begin{array}{l}84 \\
78\end{array}$ & $\begin{array}{l}0 \cdot 047 \\
0.058\end{array}$ & $\begin{array}{r}30 \\
9\end{array}$ & $\begin{array}{l}12 \\
34\end{array}$ & $\begin{array}{r}31 \\
7\end{array}$ & $\begin{array}{l}\text { II } \\
28\end{array}$ \\
\hline
\end{tabular}

* $\mathrm{I}=m e-2^{2} \times m e-2^{3}$

$t=m e-2^{1} \times m e-2^{3}$.

$\ddagger=m e-2^{2} \times m e-2^{1}$ where alleles $m e-2^{1}$ and $m e-2^{2}$ have low conversion rates and $m e-2^{8}$ a high conversion rate.

Prototrophs classified into four classes according to the combination of marker genes they carry. 
of the me-2 gene and that group $\mathrm{E}$ mutants are not deletions of a subunit.

(c) Intergroup crosses (table 3). (I) Interallelic crossing-over. The methionine prototrophs are classified as either parental, or recombinant, with respect to the marker genes. The significant excess of methionine prototrophs in one of the recombinant classes, and a reciprocal relationship in reciprocal crosses, is evidence for a linear order of alleles (Case and Giles, 1958a). Wherever sufficient numbers of prototrophs were isolated, with the exception of the cross $\mathrm{Hg}_{9}$ pan $\times \mathrm{K}_{23}$ tryp, the deviation of the recombinant classes from a I : I ratio was always significant at the o.or probability level. In the exceptional cross the excess of one of the recombinant classes was almost significant at the 0.05 probability level whilst in the reciprocal cross the alternative recombinant class was significantly in excess of the $0 \cdot$ or probability level. From these data it was concluded that there is a linear order of the alleles and the sequence of these with respect to tryp-4 and pan-I was inferred. The order derived is tryp-4, $\mathrm{K}_{44}$ (group D), K23 (F), P99 and $\mathrm{H}_{98}$ (E), Pr69 (B), P8I (C), pan-I. This is in agreement with one of the possible arrangements based on heterocaryon complementation which requires groups $D$ and $\mathrm{E}$ to be adjacent, but differs from the one expected if the most vigorous heterocaryons are between the most widely separated alleles.

(2) Conversion. Non-reciprocal recombination may account for approximately 50 per cent., or more, of the methionine prototrophs isolated. A notable feature is the marked asymmetry in the distribution of the prototrophs between the two parentally marked classes. In reciprocal crosses the excess was in the alternate parental class, indicating that the effect is characteristic of the me-2 alleles rather than of the markers or associated factors. Recombination by conversion apparently occurred more frequently at some sites than others.

If alleles $m e-2^{1}$ and $m e-2^{2}$ have low conversion rates and an allele $m e-2^{3}$ a high conversion rate then in the crosses tryp $m e-2^{1} p a n^{+}$, or tryp $m e-2^{2}$ pan $^{+}, \times$tryp $p^{+} m e-2^{3}$ pan a marked asymmetry in the distribution of the non-recombinant prototrophs would be expected, with the excess contributing to the parental class carrying the pan marker. Recombination by conversion would be expected less frequently for the cross tryp $m e-2^{1} p a n^{+} \times \operatorname{try} p^{+} m e-2^{2} p a n$, and the asymmetry in the two parental classes, if present, would be less distinct. Taking mutants $\mathrm{K}_{23}, \mathrm{~K}_{44}$ and $\mathrm{H}_{98}$ as $m e-2^{1}, m e-2^{2}$ and $m e-2^{3}$ respectively, mutant $m e-2^{3}$ exhibited the predicted high conversion rate in both crosses. Sufficient numbers of spores have not been screened from the cross $m e-2^{1} \times m e-2^{2}$ to provide significant information. Amongst the few prototrophs isolated from the latter cross there were no representatives of the parental classes.

(3) Map construction. The genetic map of the me-2 gene, in fig. 2, was constructed using the data listed in table 3. Where data 
were from reciprocal crosses involving two alleles, the frequency of prototroph formation was calculated as the weighted mean. In drawing a comparable complementation map the segments of the locus are chosen arbitrarily as being mid-way between neighbouring representatives of adjacent segments.

\section{DISCUSSION}

The formation of prototrophs in interallelic crosses is consistent with the interpretation that the alleles represent point mutations at different sites within the locus. Consideration of the markers carried by the methionine prototrophs indicates that recombination occurs by interallelic crossing-over and by conversion. An excess of methionine prototrophs in one of the "cross-over" classes with the excess in the

\section{Genetic map of locus me-2}

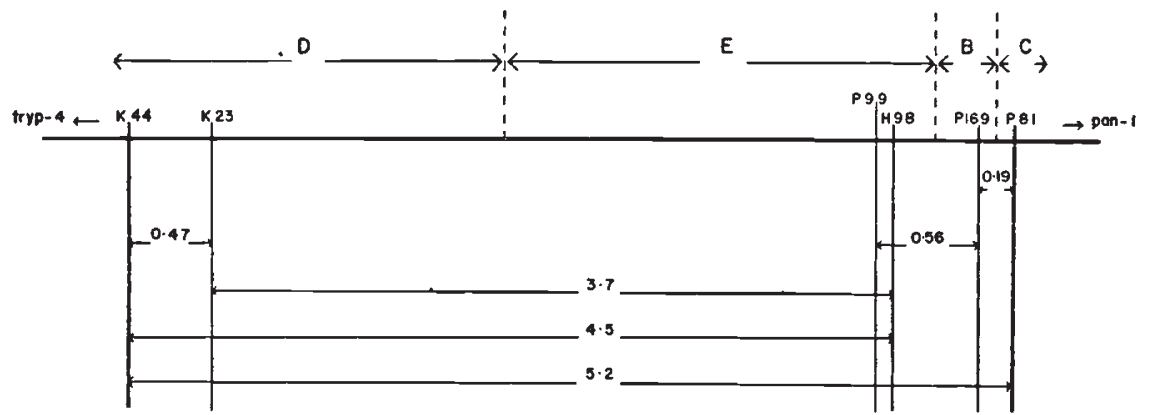

FIG. 2.-Genetic map of methionine-2, showing the order and spacing of the sites of mutation in members of complementation classes $\mathrm{B}$ to $\mathrm{F} ; \mathrm{K}_{23}$ is in group $\mathrm{F}$. The distances are expressed as prototroph frequencies per ten thousand. The limits of the complementation " regions" are drawn arbitrarily midway between neighbouring mutants belonging to different groups.

alternative "cross-over" class, when the cross is reciprocally marked, is evidence for a linear order of alleles. This property has been utilised in the determination of the sequence of the alleles studied. A small sample of the $m e-2$ alleles has been located on a genetic map and the intersite intervals, expressed as prototroph frequencies, are additive. Suyama, Munkres and Woodward (1959) in a detailed investigation of the pyr-3 locus of Neurospora demonstrated a linear additivity of prototroph frequencies although conversion rather than crossing-over was probably the major source of prototrophs. This indicates that the probability of conversion is a function of the distance between the two mutant sites involved. In the present study the evidence suggests that some alleles have high conversion rates and other alleles have low conversion rates. Therefore, a precise additivity of total prototroph frequencies might not have been expected. However, the precise additivity obtained might be fortuitous, for the major distances of the map in fig. 2 are based on prototroph frequencies 
from crosses involving one allele with a high conversion rate and one allele with a low conversion rate.

If the prototroph frequencies are an estimate of the linear distance between mutant sites, the subunits of the gene must vary in length, for segment $\mathrm{B}$ must be small in comparison with segment $\mathrm{D}$ or $\mathrm{E}$. The interpretation that the genetic length of the segment reflects the number of mutable sites is consistent with the finding that of the twelve complementing alleles only two were located in groups $\mathrm{B}$ and $\mathrm{C}$, while ten were in groups $\mathrm{D}, \mathrm{E}$, and the overlapping group $\mathrm{F}$. This unequal distribution of alleles has been observed at the his-3 locus (Catcheside, I960), the arg-I locus (Catcheside and Overton, I958) and the ad-4 locus (Woodward et al., I958). Differences in mutation rates, in the number of mutable sites, or a combination of these two factors could be responsible for these distributions.

The occurrence of high prototroph frequencies in the crosses between two non-complementing (group A) alleles indicates that these are neither deletions, nor point mutations confined to a short region of the locus. Case and Giles ( $195^{8} b$ ) reported that the noncomplementing alleles are scattered throughout the length of the pan-2 locus and some may even be at the same sites as complementing alleles. It would be desirable to map some of the non-complementing $m e-2$ alleles with respect to alleles of the complementation groups.

The data are in full agreement with a direct correlation between genetic and complementation maps, suggesting that the four physiological subunits of the $m e-2$ gene can be translated into linear segments of the genetic map. It is probable, that a mutation at a site in segment $\mathrm{D}$, of the me-2 locus, produces a mutant which according to complementation data may be in group A, group D, or a group whose range of action overlaps that of mutants of group $\mathrm{D}$ and of one or more adjacent groups. For example, mutant $\mathrm{K}_{23}$ (group F), whose range of action overlaps segments $D$ and $E$ is located in segment $D$. These findings may be taken as evidence that both the precise location of a mutation and the nature of the mutational change determine the nature of the alteration of the gene product.

The correlation between map distance and degree of restoration of enzyme activity, which has been demonstrated at the ad-4 locus (Woodward et al., I958), has been interpreted as evidence for an explanation of complementation involving recombination at the gene product level. The striking lack of correlation at the $m e-2$ locus is consistent with the recent enzyme studies of Fincham (1959) which exclude recombination at the gene product level to give some normal product, or template, capable of catalysing the synthesis of an enzyme not qualitatively different from that of wild type.

Some alleles at locus $m e-2$ give rise to prototrophs by conversion, more frequently than do others. This observation favours nonreciprocal recombination by a mechanism other than one involving crossing-over. Stadler (I959) reports that in a cross between two 
cys mutants of $\mathcal{N}$ eurospora, one of the mutants consistently gives rise to cysteine prototrophs by conversion more frequently than does the other. He further states that inequalities amongst the recombinant classes would be expected in the absence of interallelic crossing-over if:

(a) gene conversion and crossing-over are two separate events;

(b) one allele is converted more frequently than the other;

(c) the amount of crossing-over in the adjacent marked region on the left of the locus is different from that on the right.

Stadler found this explanation untenable for his data.

When the conditions listed are applied to the me-2 alleles the most frequent class of methionine prototroph, which is recombinant with respect to the marker genes, would be that produced by the more frequent conversion accompanied by the more frequent crossover. For example, in the cross tryp $\mathrm{K}_{44}$ pan $^{+} \times \operatorname{tryp}^{+} \mathrm{P} 8 \mathrm{I}$ pan, where $\mathrm{K}_{44}$ has a low conversion rate and $\mathrm{P} 8 \mathrm{I}$ a high conversion rate, there would be more crossing-over in the longer marked region to the left of the $m e-2$ alleles than there would be in the shorter marked region to the right. The more frequent recombinant methionine prototrophs should carry the tryp marker from the $\mathrm{K}_{44}$ parent and the pan marker from the P8I parent. However, this was found to be the less frequent recombinant class. The same discrepancy has been observed for all the crosses made between alleles of apparently very different conversion rates.

In the present discussion it has been assumed that recombination between $m e-2$ alleles resembles that found between pan-2 alleles (Case and Giles, $195^{8} a, \mathrm{I} 95^{8 b}$ ), and hence that there are two mechanisms of recombination, one of which is interallelic crossing-over. Confirmation should be obtained by tetrad analysis that at least some of the excess recombinant class arise by inter-allelic crossing-over, but this is impractical in view of the low frequencies of recombination.

\section{SUMMARY}

Amongst 44 methionine-2 strains of Neurospora crassa, twelve have been demonstrated to be capable of interallelic complementation. Genetic and complementation maps have been constructed. The use of marker genes on either side of the me-2 locus has facilitated the demonstration of interallelic crossing-over and conversion. These studies also indicate a linear arrangement of mutable sites within the gene, with additive prototroph frequencies, to yield a map which can be correlated with a complementation map. Growth assays suggest that there is no correlation between the degree of complementation and the distance between two mutant sites. Evidence is provided that some alleles have higher conversion rates than others.

Acknowledgments. - The author is indebted to Professor D. G. Catcheside, F.R.s., for helpful discussion and criticism given during these investigations and to $\mathrm{Dr} D$. D. Perkins for his encouragement and hospitality during the writing of this paper. 


\section{REFERENCES}

AHMAD, M., AND CATCheside, D. G. I96o. Physiological diversity amongst tryptophan mutants in Neurospora crassa. Heredity, ${ }_{5}, 55-64$.

BARRATT, R. W., NEWMEYER, D., PERkINS, D., AND GARNJOBST, L. I954. Map construction in Neurospora crassa. Adv. in Genetics, 6, I-93.

CASE, M., AND GILES, N. H. I958a. Evidence from tetrad analysis for both normal and aberrant recombination between allelic mutants in Neurospora crassa. Proc. Nat. Acad. Sci., Wash., 44, 378-39o.

CASE, M., AND GILES, N. H. I958b. Recombination mechanisms at the pan-2 locus in Neurospora crassa. Cold Spring Harbor Symp. Quant. Biol., 23, I I9-1 35.

CATCHESIDE, D. G. I954. Isolation of nutritional mutants of Neurospora crassa by filtration enrichment. 7. Gen. Microbiol., rI, 34-36.

CATCheside, D. G. I96o. Microbial Genetics. Relation of genotype to enzyme content. Tenth Symp. Soc. Gen. Microbiol., pp. 181-207.

CATCheside, D. G., AND OVERTON, ANNE. I958. Complementation between alleles in heterocaryons. Cold Spring Harbor Symp. Quant. Biol., 23, I37-I40.

FINCHAM, J. R. S. I959. On the nature of the enzyme produced by inter-allele complementation at the am locus in Neurospora crassa. 7. Gen. Microbiol., 2r, 6oo-6 I I.

FREESE, E. I957. The correlation effect for a histidine locus of Neurospora crassa. Genetics, 42,67I-684.

GILES, N. H. I95I. Studies on the mechanism of reversion in biochemical mutants of Neurospora crassa. Cold Spring Harbor Symp. Quant. Biol., r6, 283-313.

GILES, N. H. I956. Forward and back mutation at specific loci in Neurospora. Brookhaven Symp. Biol., 8, 103-105.

LEUPOLD, U. 1957. Physiologisch-genetische Studien an adeninabhängigen Mutanten von Schizosaccharomyces pombe. Ein Beitrag zum Problem der Pseudoallelie. Schweiz. z. allg. Path. Bakt., 20, 535-544.

LEWIS, E. B. I945. The relation of repeats to position effect in Drosophila melanogaster. Genetics, 30, 137-I66.

LINDEGREN, c. C. I953. Gene conversion in Saccharomyces. 7. Genet., 5r, 625-637.

MITCHELI, M. в. I955a. Aberrant recombination of pyridoxine mutants of Neurospora. Proc. Nat. Acad. Sci., Wash., 4I, 2 I 5-220.

MITCHELI., M. B. I955 b. Further evidence of aberrant recombination in Neurospora. Proc. Nat. Acad. Sci., Wash., 4I, 935-937.

MURRAY, N. E. I96o. The distribution of methionine loci in Neurospora crassa. Heredity, 15, 199-206.

NEWMEYER, D. L. I954. A plating method for genetic analysis in Neurospora. Genetics, 39, 604-6 18 .

PRITCHARD, R. H. I955. The linear arrangement of a series of alleles of Aspergillus nidulans. Heredity, 9, 343-37 I.

Roman, H. I956. Studies on gene mutation in Saccharomyces. Cold Spring Harbor Symp. Quant. Biol., 21, I75-185.

st lawrence, P. 1956. The $q$ locus of Neurospora crassa. Proc. Nat. Acad. Sci., Wash., 42, I 89-194.

STADLER, D. R. I959. Gene conversion of cysteine mutants in Neurospora. Genetics, $44,647-655$.

SUYAMA, V., MUNKRes, K. D., AND WOodWARD, v. W. I959. Genetic analysis of the pyr-3 locus of Neurospora crassa: the bearing of recombination and gene conversion upon intra-allelic linearity. Genetica, 30, 293-3 I I.

WOoDWARD, D. o. I959. Enzyme complementation in vitro between adenylosuccinaseless mutants of Neurospora crassa. Proc. Nat. Acad. Sci., Wash., 45, $846-850$.

WOOdWARD, D. o., PARTRIDGE, c. W. H., AND Giles, N. H. I958. Complementation at the ad-4 locus in Neurospora crassa. Proc. Nat. Acad. Sci., Wash., 44, I 237-1 244. 